\title{
Kemampuan Soft Skills Guru Penjasorkes Kelompok Kerja MTS Jepara Tahun 2019
}

\author{
Lusiana $^{1}$, Yudhi Purnama ${ }^{2}$ \\ Program Studi Pendidikan Jasmani Kesehatan dan Rekreasi Fakultas \\ Keguruan dan Ilmu Pendidikan Universitas Wahid Hasyim ${ }^{1,2}$ \\ lusianaprabowo@gmail.com ${ }^{1}$,purnama1725@gmail.com ${ }^{2}$
}

\begin{abstract}
Abstrak
Seorang Guru harus mempunyai kemampuan soft skills yang baik sebagai penunjang menjadi guru yang profesional. Kemampuan soft skills menjadi bagian dari kompetensi kepribadian dan sosial. Tujuan penelitian ini adalah untuk mengetahui kemampuan soft skills Guru Penjasorkes Kelompok Kerja MTs Jepara Tahun 2018. Metode penelitian menggunakan survei dengan pendekatan penelitian deskriptif kuantitatif. Data diperoleh dengan angket selfreport. Populasi sebanyak 66 Guru Penjasorkes, sampel diambil dengan teknik accidental sampling yaitu ketika peneliti menjadi narasumber dalam workshop kurikulum 2013 Penjasorkes. Sebanyak 50 Guru Penjasorkes yang hadir dijadikan sebagai sampel. Analisis data menggunakan analisis statistik deskriptif kuantitatif dengan prosentase. Hasil penelitian diketahui bahwa aspek keterampilan berkomunikasi prosentae 80,30\%, aspek keterampilan berpikir kritis dan memecahkan masalah 80,65\%, aspek kerja tim 79,08\%, aspek keterampilan belajar manajemen informasi $81,30 \%$, aspek kewirausahaan mendapatkan 76,60\%, aspek etika dan moral 79,60\% dan aspek keterampilan kepemimpinan 83,73\%. Disimpulkan bahwa kemampuan soft skills guru penjasorkes di KKMTs Kabupaten Jepara Tahun 2019 masuk dalam kategori baik sekali dengan prosentase rata-rata sebesar 80,18\% .
\end{abstract}

Kata Kunci : Kemampuan Soft Skills, Guru Penjasorkes

\section{Skills of Penjasorkes Teacher Soft Skills Jepara MTS Working Group of 2019}

\begin{abstract}
A teacher must have a good soft skill to be a professional teacher. Soft skills ability to became part of the personality and social competence. This research purpose is to knowing the soft skill ability of education and healthy teachers in the workgrup at MTS Jepara 2018 year. The research method used suvey with descriptive cuantitave approach. The result of the data got from the questionnaire self-report. The population in this reseach is 66 peoples, and the sample used accident sampling technique,the accident sampling technique is The researcher being facilitator in the 2013 curicculum workshop to education sport and healthty teachers, with sample is 50 peoples, they are participants who attended the workshop event. The data analysis used analysis technique of quantitative descriptive percentage. The result research from communication skills aspect is $80,30 \%$, critical thingking and problems solving skills aspect is 80,65\%, management learning skills aspect is $81,30 \%$, entrepreneurship aspect is 76,60\%, ethnicals and moral aspect is 79,60\% and the leadership aspect is $83,73 \%$. The summary is the soft skill ability at physical education sport and healty teachers in KKMTs Jepara Region, they are showing level "very Good" category value $80,81 \%$.
\end{abstract}




\section{PENDAHULUAN}

Perkembangan dan pembangunan bangsa yang maju, modern, makmur dan sejahtera tidak lepas dari sumber daya manusia yang baik. Salah satu cara untuk dapat meningkatkan SDM yang kompeten dan berkualitas serta dapat diandalkan diantaranya melalui pendidikan, baik yang diberikan secara formal di institusi pendidikan maupun pendidikan informal yang berkembang di masyarakat.

Dunia pendidikan memiliki struktur yang tersusun dari berbagai elemen, baik dari yang mendasar (guru/sumber daya manusia) sampai infrastruktur yang mendukung proses pendidikan. Guru merupakan subjek terdepan yang sangat menentukan pencapaian tujuan pendidikan nasional. Untuk menjamin tercapainya tujuan pendidikan, semua guru harus berkualitas di bidangnya, termasuk guru pendidikan jasmani olahraga dan kesehatan (penjasorkes).

Profesi guru penjasorkes secara umum sama dengan guru mata pelajaran yang lain pada umumnya, namun secara khusus ada letak perbedaan tersendiri. Menjadi guru penjasorkes yang berkualitas tidak semudah yang dibayangkan orang selama ini. Salah jika ada yang menganggap mereka hanya dengan modal peluit bisa menjadi guru penjasorkes di sekolah. Justru sebaliknya, lebih sulit menjadi seorang guru penjasorkes yang berkualitas dibandingkan dengan guru mata pelajaran yang lain. Guru penjasorkes tidak hanya bertugas untuk menyampaikan teori saja,akan tetapi dituntut juga untuk mengajarkan praktik secara utuh bagaimana melakukan gerakan-gerakan yang benar. Oleh karena itu guru penjasorkes harus mempunyai kemampuan hard skills dan soft skills yang baik.

Undang-Undang Nomor 14 Tahun 2005 tentang Guru dan Dosen, pada pasal 10 ayat (1) menyatakan bahwa "Kompetensi guru meliputi kompetensi pedagogik, kompetensi kepribadian, kompetensi sosial, dan kompetensi profesional yang diperoleh melalui pendidikan profesi”. Kompetensi guru merupakan kebulatan pengetahuan, keterampilan dan sikap yang berwujud tindakan cerdas dan penuh tanggung jawab dalam melaksanakan tugas sebagai agen pembelajaran.

Guru penjasorkes yang berkualitas dan profesional harus memiliki empat kompetensi atau standar kemampuan yang meliputi: kompetensi pedagogik, kompetensi kepribadian, kompetensi sosial, dan kompetensi profesional. Secara tidak langsung dari empat kompetensi guru di atas mencakup tentang hard skills (kompetensi pedagogik dan profesional) dan soft skills (kompetensi kepribadian dan sosial). Kompetensi pedagogik yaitu kemampuan 
pemahaman terhadap peserta didik, perancangan dan pelaksanaan pembelajaran, evaluasi hasil belajar, dan pengembangan peserta didik untuk mengaktualisasikan berbagai potensi yang dimilikinya. Sedangkan kemampuan profesional yaitu penguasaan materi pembelajaran secara luas dan mendalam, yang mencakup penguasaan materi kurikulum mata pelajaran di sekolah dan substansi keilmuan yang menaungi materi serta penguasaan terhadap struktur dan metodologi keilmuannya.

Untuk mendukung dua kompetensi di atas guru juga dituntut memiliki kompetensi kepribadian dan kompetensi sosial. Kompetensi kepribadian adalah kemampuan personal yang mencerminkan kepribadian yang mantap, stabil, dewasa, arif dan berwibawa, menjadi teladan bagi peserta didik, dan berakhlak mulia. Dan kompetensi sosial yaitu kemampuan guru untuk berkomunikasi dan bergaul secara efektif dengan peserta didik, tenaga kependidikan, orang tua/wali peserta didik, dan masyarakat sekitar.

Kemampuan hard skills dan soft skills seorang guru penjasorkes dapat diamati pada saat pembelajaran, seperti halnya pada saat pembelajaran senam lantai, seorang guru penjasorkes dapat mempraktikan bagaimana cara guling depan, guling depan, kayang, sikap lilin, dan lain-lain dengan baik dihadapan siswa, karena hard skills menggambarkan perilaku dan keterampilan yang dapat dilihat mata. Sedangkan soft skills merupakan kecakapan dalam mengendalikan kepribadian, kemampuan bekerja sama, mengambil inisiatif, keberanian mengambil keputusan, mampu beradaptasi, mampu memecahkan masalah dan cara mengajar dengan ramah, hangat, serta dapat berkomunikasi baik dengan siswa.

Selain itu untuk mengembangkan kemampuan soft skills, guru penjasorkes dapat mengikuti berbagai organisasi keolahragaan, pelatihan dan seminar tentang pendidikan jasmani kesehatan dan olahraga. Di samping itu peningkatan soft skills guru penjasorkes melalui pembinaan pada kegiatan akademis maupun nonakademis perlu dilakukan secara optimal, ditambah dengan pembelajaran aspek akademik berupa ilmu pengetahuan, teknologi dan seni sebagai hard skills. Dengan begitu guru penjasorkes dituntut untuk mengembangkan kemampuan soft skills agar dapat bersaing dalam bidangnya. Menjadi seorang guru penjasorkes harus selalu melakukan perbaikan dan pengembangan soft skills, sehingga diharapkan selalu ada peningkatan soft skills untuk mendukung menjadi guru penjasorkes yang kompeten dan berkualitas. Untuk dapat melakukan perbaikan guru penjasorkes perlu mengetahui kemampuan soft skills yang dimiliki oleh 
masing-masing individu. Guru penjasorkes juga dapat mengembangkan soft skills dengan mengikuti kegiatan yang diadakan oleh pihak pemerintah maupun lembaga lain seperti seminar, workshop, dan pelatihan keorganisasian. Jadi setelah guru penjasorkes memiliki hard skills yang memadai mereka juga memiliki kemampuan untuk mengaplikasikan soft skills yang dimiliki dalam pembelajaran.

Berdasarkan data dari Kelompok Kerja Madrasah Tsanawiyah (KKMTs) Kabupaten Jepara Tahun 2019 bahwa 50\% guru penjasorkes belum linier, artinya bukan lulusan pendidikan jasmani/olahraga. Dengan demikian secara administrasi guru penjasorkes di KKMTs Kabupaten Jepara masih belum layak. Sampai saat ini belum diketahui kemampuan soft skills guru penjasorkes.. Maka hal tersebut mendorong peneliti untuk melakukan penelitian tentang kemampuan soft skills guru pendidikan jasmani olahraga dan kesehatan KKMTs Kabupaten Jepara Tahun 2019, guna sebagai evaluasi diri, baik untuk guru penjasorkes dan pihak-pihak penyelenggara pendidikan untuk senantiasa meningkatkan kemampuan soft skills guru sebagai modal utama untuk meraih kesuksesan dan keberhasilan menjadi guru yang profesional, berkepribadian dan berkualitas baik hard skills maupun soft skills.

\section{KAJIAN TEORI}

Soft skills merupakan keterampilan dan kecakapan hidup, baik untuk sendiri, berkelompok, atau bermasyarakat, serta dengan sang pencipta. Selebihnya dengan mempunyai soft skills membuat keberadaan seseorang akan semakin terasa di masyarakat (Elfindri, 2010: 67). Sedangkan menurut I Nyoman Sucipta (2009: 1), soft skills adalah kunci menuju hidup yang lebih baik, sahabat lebih banyak, sukses lebih besar, kebahagiaan yang lebih luas, tidak punya nilai, kecuali diterapkan dalam kehidupan sehari-hari baru bernilai. Ditambahkan lagi bahwa soft skills adalah kemampuan yang berkaitan dengan hubungan antar manusia, seperti bagaimana melakukan conflict resolution, memahami personal dynamics, dan melakukan negosiasi.

Dalam sumber lain menyebutkan bahwa soft skills adalah seperangkat kemampuan yang mempengaruhi bagaimana kita berinteraksi dengan orang lain. Soft skills memuat komunikasi efektif, berpikir kreatif dan kritis, membangun tim, serta kemampuan lainnya yang terkait kapasitas kepribadian individu. Tujuan dari pelatihan soft skills adalah memberikan kesempatan kepada individu untuk mempelajari perilaku baru dan meningkatkan hubungan antar pribadi dengan orang lain (Wahyu Widhiarso, 2009).

Ada tujuh soft skills yang diidenfikasi dan penting dikembangkan pada peserta didik 
di lembaga pendidikan tinggi menurut I Made S. Utama dkk (2010: 3), yaitu meliputi; keterampilan berkomunikasi (communicative skills), keterampilan berpikir dan menyelesaikan masalah (thinking skills and problem solving skills), kekuatan kerja tim (team work force), belajar sepanjang hayat dan pengelolaan informasi (life-long learning and information management), keterampilan wirausaha (entrepreneur skill), etika, moral dan profesionalisme (ethics, moral and professionalism), dan keterampilan kepemimpinan (leadership skills).

Soft Skills give Hard Skills the required plasticity to develop and keep up-to-date in changing circumstances. Soft Skills are closely related to plastic, rational, elaborating, abilities, elaborated in the prefrontal cortex, developed by Man in the last 50.000 years. Soft Skills operate in a direction that is rather separate from the role of the individual and go beyond the strict demands of the profession (Grisi, 2014).

Menurut Muqowin (2012: 12), ada beberapa alasan tentang pentingya peran soft skills sebagai kompetensi kepribadian dan sosial guru. Kompetensi kepribadian dan sosial lebih substantif daripada kompetensi profesional dan pedagogik, sehingga jika kedua kompetensi soft skills tersebut dimiliki guru, maka kompetensi profesional dan pedagogig secara otomatis akan dapat teratasi.
Asmuni (2014) menyatakan bahwa yang paling menentukan kesuksesan didunia kerja bukanlah hard skills melainkan kualitas diri yang termasuk dalam katagori keterampilan lunak (softskills) atau keterampilan berhubungan dengan orang lain (people skills), yang sekaligus menjadi karakter mereka.

Soft Skills are then considered a strategic element in any industrial organization and they deserve high attention from the Human Resources management, not only in the recruitment phase but also during the whole professional career of employees (Cimatti, 2016)

Dari beberapa pengertian di atas, maka dapat disimpulkan bahwa soft skills adalah kemampuan pengembangan diri yang digunakan untuk berinteraksi dengan orang lain dengan proses pertukaran dan transformasi pesan, verbal ataupun nonverbal, secara individu dan kelompok.

Supardi dalam bukunya yang berjudul "Kinerja Guru" menjelaskan pengertian guru menurut Undang-Undang Republik Indonesia Nomor 14 Tahun 2005 tentang Guru dan Dosen, bahwa guru adalah pendidik profesional dengan tugas utama mendidik, mengajar, membimbing, mengarahkan, melatih, menilai, dan mengevaluasi peserta didik pada pendidikan usia dini, pendidikan 
dasar, dan pendidikan menengah jalur pendidikan formal.

Guru yang menjalankan tugasnya dengan baik disebut guru yang professional, yakni memiliki beberapa keahlian atau kompetensi meliputi pedagogic, kepribadian, sosial dan professional yang terjalin satu dengan yang lain (Shabir 2015).

Menjadi guru berarti menyandang dua status, yakni professional dan pendidik. Guru professional bukan semata-mata berorientasi mendapatkan pekerjaan dan pendapatan yang layak, melainkan juga memiliki panggilan jiwa dan kesadaran humanis (Warsono, 2017) Menurut Dwi Siswoyo (2007: 126), pendidik adalah setiap orang yang dengan sengaja mempengaruhi orang lain untuk mencapai tingkat kemanusiaan yang lebih tinggi. Sedangkan menurut Subagiyo dkk (2008: 18) pendidikan jasmani adalah latihan jasmani yang dimanfaatkan, dikembangkan dan didayagunakan dalam pendidikan. Jadi guru pendidikan jasmani adalah guru yang mempunyai kemampuan dan keterampilan pendidikan jasmani, olahraga dan kesehatan untuk mendidik, mengajar, membimbing, mengarahkan, melatih, menilai, dan mengevaluasi setiap peserta didik. Oleh karena itu guru penjasorkes memerlukan kemampuan hard skills dan soft skills yang baik agar dapat menciptakan sumber daya manusia yang berdaya saing.

\section{METODE PENELITIAN}

Metode penelitian menurut Sugiyono (2014: 2) adalah cara ilmiah untuk mendapatkan data dengan tujaun dan kegunaan tertentu. Penelitian ini menggunakan metode survei dengan pendekatan kuantitatif deskriptif, dengan instrument angket self-report. Penelitian deskriptif memusatkan perhatian pada masalah-masalah aktual sebagaimana adanya pada saat penelitian berlangsung (Trianto, 2010: 197). Sedangkan penelitian kuantitatif adalah suatu proses menemukan pengetahuan yang menggunakan data berupa angka sebagai alat untuk menganalisis keterangan mengenai apa yang ingin diketahui (Kasiram, 2008: 149). Penelitian survei adalah penelitian yang dilakukan pada populasi besar maupun kecil, tetapi data yang dipelajari adalah data dari sampel yang diambil dari populasi tersebut, sehingga ditemukan kejadian-kejadian relative, distribusi, dan hubungan-hubungan antar variabel sosiologis maupun psikologis (Sugiyono, 2014: 7).

Design penelitian ini adalah penelitian survei dengan pendekatan kuantitatif deskriptif, pengambilan data menggunakan angket. Tujuan dari penelitian ini adalah untuk mengetahui gambaran umum tentang kemampuan soft skills Guru Penjasorkes KKMTs Kabupaten Jepara Tahun 2019. 
Penelitian ini dilakukan pada saat peneliti menjadi narasumber pada acara workshop kurikulum 2013 Penjasorkes di KKMTs Kabupaten Jepara, 7 Januari 2019. Populasi dalam penelitian ini adalah 66 guru penjasorkes. Peneliti menggunakan teknik penarikan accidental sampling, yaitu 50 guru penjasorkes yang hadir pada saat acara tersebut. Variabel dalam penelitian ini adalah kemampuan soft skills Guru Penjasorkes MTs
se-KKMTs Kabupaten Jepara Tahun 2019 dengan tujuan untuk mengetahui kepribadian dan sosial dari guru tersebut, hubungannya dengan menjadi seorang guru yang profesional.

Menurut Sugiyono (2009: 148) instrument adalah alat ukur dalam penelitian yang digunakan mengukur fenomena alam maupun sosial yang diamati. Instrumen dalam penelitian ini berupa angket self-report.

Tabel 1. Kisi-kisi Angket Penelitian Soft Skills Guru Penjasorkes

\begin{tabular}{|c|c|c|c|}
\hline No. & Aspek & Indikator & Butir Nomor \\
\hline \multirow[t]{3}{*}{1.} & \multirow[t]{3}{*}{$\begin{array}{l}\text { Keterampilan } \\
\text { berkomunikasi }\end{array}$} & $\begin{array}{l}\text { Kemampuan mengemukakan pendapat dengan } \\
\text { jelas, efektif dan penuh percaya diri baik lisan } \\
\text { maupun tulisan }\end{array}$ & $1,2,3,4,5$ \\
\hline & & $\begin{array}{l}\text { Kemampuan menyimak dan merespon aktif dan } \\
\text { menghargai orang lain }\end{array}$ & $6,7,8,9$ \\
\hline & & $\begin{array}{l}\text { Kemampuan meyakinkan pendapat kepada orang } \\
\text { lain dengan percaya diri }\end{array}$ & $10,11,12,13$ \\
\hline \multirow[t]{3}{*}{2.} & \multirow{3}{*}{$\begin{array}{l}\text { Keterampilan } \\
\text { berpikir kritis dan } \\
\text { memecahkan } \\
\text { masalah }\end{array}$} & $\begin{array}{l}\text { Kemampuan mengidentifikasi dan menganalisa } \\
\text { masalah dalam situasi yang sulit serta membuat } \\
\text { keputusan yang tepat }\end{array}$ & $\begin{array}{l}14,15,16,17, \\
18\end{array}$ \\
\hline & & $\begin{array}{l}\text { Kemampuan memperluas dan meningkatkan } \\
\text { keterampilan berpikir }\end{array}$ & $19,20,21,22$ \\
\hline & & $\begin{array}{l}\text { Kemampuan menemukan gagasan dan mencari } \\
\text { solusi alternative }\end{array}$ & 23,24 \\
\hline \multirow[t]{2}{*}{3.} & \multirow[t]{2}{*}{ Kerja tim } & $\begin{array}{l}\text { Kemampuan bekerja sama, berinteraksi dan } \\
\text { membangun hubungan yang baik }\end{array}$ & $25,26,27$ \\
\hline & & $\begin{array}{l}\text { Kemampuan dalam menghormati sikap, perilaku } \\
\text { dan pendirian orang lain. }\end{array}$ & $28,29,30,31$ \\
\hline \multirow[t]{3}{*}{4.} & \multirow[t]{3}{*}{$\begin{array}{l}\text { Keterampilan } \\
\text { belajar manajemen } \\
\text { informasi }\end{array}$} & $\begin{array}{l}\text { Kemampuan menemukan dan mengelola informasi } \\
\text { dari berbagai sumber }\end{array}$ & $32,33,34$ \\
\hline & & $\begin{array}{l}\text { Kemampuan dalam menerima gagasan baru dari } \\
\text { orang lain }\end{array}$ & $35,36,37$ \\
\hline & & Kemampuan dalam kemandirian belajar & 38,39 \\
\hline 5. & $\begin{array}{l}\text { Keterampilan } \\
\text { kewirausahaan }\end{array}$ & $\begin{array}{l}\text { Kemampuan mengidentifikasi kesempatan kerja } \\
\text { dan memanfaatkan peluang kerja }\end{array}$ & $40,41,42,43$ \\
\hline 6. & Etika dan moral & $\begin{array}{l}\text { Kemampuan menganalisa dan membuat keputusan } \\
\text { terkait dengan etika dan moral }\end{array}$ & $\begin{array}{l}44,45,46,47 \\
48,49,50,51\end{array}$ \\
\hline 7. & $\begin{array}{l}\text { Keterampilan } \\
\text { kepemimpinan }\end{array}$ & $\begin{array}{l}\text { Kemampuan memahami dan berperan sebagai } \\
\text { seorang pemimpin atau bawahan secara bergantian } \\
\text { dengan baik }\end{array}$ & 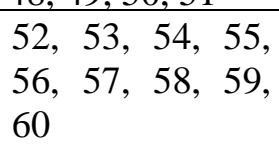 \\
\hline
\end{tabular}


Teknik analisis deskriptif kuantitatif menggunakan prosentase dari skor angket yang diperoleh guru penjasorkes. Kemudian hasilnya dikategorikan menjadi lima kategori, yaitu baik sekali, baik, sedang, kurang baik dan tidak baik.

Tabel 2. Skala

\begin{tabular}{ccl}
\hline No. & Prosentase & \multicolumn{1}{c}{ Kategori } \\
\hline 1. & $80 \%-100 \%$ & Baik sekali \\
\hline 2. & $60 \%-80 \%$ & Baik \\
\hline 3. & $40 \%-60 \%$ & Sedang \\
\hline 4. & $20 \%-40 \%$ & Kurang baik \\
\hline 5. & $0 \%-20 \%$ & Tidak baik \\
\hline
\end{tabular}

\section{HASIL PENELITIAN}

Data hasil penelitian diperoleh dari angket self-report yang diisi oleh responden (guru penjasorkes), adapun hasil kemampuan soft skills dapat dilihat melalui tabel di bawah ini:

Tabel 3. Analisis Data Hasil Penelitian

\begin{tabular}{|c|c|c|c|c|c|c|c|}
\hline No. & Aspek & Jumlah & Min & Mak & Rata2 & $\%$ & Kategori \\
\hline 1. & Keterampilan berkomunikasi & 2610 & 47 & 59 & 52,20 & $80,30 \%$ & baik sekali \\
\hline 2. & $\begin{array}{l}\text { Keterampilan berpikir kritis } \\
\text { dan memecahkan masalah }\end{array}$ & 2218 & 35 & 52 & 44,36 & $80,65 \%$ & baik sekali \\
\hline 3. & Kerja tim & 1384 & 24 & 33 & 27,68 & $79,08 \%$ & baik \\
\hline 4. & $\begin{array}{l}\text { Keterampilan } \\
\text { manajemen informasi }\end{array}$ & 1626 & 25 & 38 & 32,52 & $81,30 \%$ & baik sekali \\
\hline 5. & Keterampilan kewirausahaan & 766 & 13 & 18 & 15,32 & $76,60 \%$ & baik \\
\hline 6. & Etika dan moral & 1592 & 26 & 36 & 31,84 & $79,60 \%$ & baik \\
\hline 7. & Keterampilan kepemimpinan & 1884 & 34 & 42 & 37,68 & $83,73 \%$ & baik sekali \\
\hline & Jumlah & & & & & $561,26 \%$ & \\
\hline & Rata-rata & & & & & $80,18 \%$ & baik sekali \\
\hline
\end{tabular}

Dari perhitungan analisis data pada tabel di atas, maka dapat diketahui bahwa; 1) aspek keterampilan berkomunikasi diperoleh prosentae sejumlah 80,30\% termasuk dalam kategori baik sekali; 2) aspek keterampilan berpikir kritis dan memecahkan masalah diperoleh prosentase $80,65 \%$ termasuk kategori baik sekali; 3) aspek kerja tim mendapatkan skor 79,08\% kategori baik; 4) aspek keterampilan belajar manajemen informasi prosentase
81,30\% kategori baik sekali; 5) aspek kewirausahaan mendapatkan prosentase $76,60 \%$ dengan kategori baik; 6) aspek etika dan moral diperoleh prosentase $79,60 \%$ kategori baik; dan 7) aspek keterampilan kepemimpinan mendapat prosentase $83,73 \%$ dengan kategori baik sekali. 


\section{KESIMPULAN}

Berdasarkan pada perhitungan analisis data dari beberapa aspek yang sudah ada, maka dapat disimpulkan bahwa kemampuan soft skills guru penjasorkes di KKMTs Kabupaten Jepara Tahun 2019 masuk dalam kategori baik sekali dengan prosentase rata-rata sebesar $\mathbf{8 0 , 1 8 \%}$.

Saran bagi Kepala Sekolah di KKMTs Kabupaten Jepara agar lebih memotivasi guru khususnya guru penjasorkes untuk meningkatkan soft skills aspek kerja tim, etika dan moral serta keterampilan kewirausahaan dengan berbagai kegiatan luar sekolah dan workshop di sekolah.

\section{DAFTAR PUSTAKA}

Asmuni. (September 2015). Pengembangan Soft Skills dan Karakter Mahasiswa untuk Menyongsong Masa Depan Cerah. Jombang: LP2i STKIP PGRI Jombang.

Cimatti, B. (Februari 2016). Definition, Development, Assessment of Soft Skills and Their Role for The Quality of Organizations and Enterprises. International Journal for Quality Research 10 (1) 97-130.

Elfindri, dkk. (2011). Soft Skills untuk Pendidik. Bandung: Baduose Media.

Grisi, C.G.A., (November 2014). Soft Skills: a close link between enterprises and ethics. Speech at "Soft Skills and their role in employability - New perspectives in teaching, assessment and certification", workshop in Bertinoro, FC, Italy.

Margono. (2009). Metodologi Penelitian Pendidikan. Jakarta: PT. Rineka Cipta.

Muhammad Muslich. (2009). Metode Pengambilan Keputusan Kuantitatif. Jakarta: PT Bumi Aksara.

Muqowin. (2012). Pengembangan Soft Skills Guru. Yogyakarta: Pedagogia.

Presiden Republik Indonesia. (2005). Undang-undang Republik Indonesia Nomor 14 Tahun 2005 tentang Guru dan Dosen. Diakses dari http://www.dikti.go.id/files/atur/UU1 4-2005 Guru Dosen.pdf. Pada tanggal 5 Maret 2019.

Shabir. (Desember 2015). Kedudukan Guru sebagai Pendidik: Tugas dan Tanggung Jawab, Hak dan Kewajiban, dan Kompetensi Guru. Jurnal Pendidikan Dasar Islam: UIN Alauddin Makassar.

Sucipta I Nyoman. (2009). Holistik Soft Skills. Denpasar: Udayana University Press.

Sugiyono. (2009). Metode Penelitian Pendidikan (Pendekatan Kuantitatif Kualitatif dan $R \& D)$. Bandung: Alfabeta.

Sugiyono. (2011). Metode Penelitian Kombinasi (Mixed Methods). Bandung: Alfabeta.

Supardi. 2014. Kinerja Guru. Jakarta: PT Raja Grafindo Persada

Warsono. 2017. Guru: Antara Pendidik, Profesi dan Aktor Sosial. Unesa: The Journal of Society dan Media Vol 1 (1) $1-10$ 